\title{
Skull Fracture Prediction through Subject-Specific Finite Element Modelling is Highly Sensitive to Model Parameters
}

\author{
Dries De Kegel ${ }^{a, *}$, Alexander Meynen ${ }^{b, *}$, Nele Famaey ${ }^{a}$, G. Harry van \\ Lenthe $^{a}$, Bart Depreitere ${ }^{c}$, Jos Vander Sloten ${ }^{a}$ \\ a. Biomechanics section, KU Leuven, Leuven, Belgium \\ b. Orthopaedic Research Center, KU Leuven, Leuven, Belgium \\ c. Department of Neurosurgery, University Hospital Gasthuisberg, KU Leuven, Leuven, \\ Belgium \\ * authors contributed equally
}

\begin{abstract}
Reliable computer models are needed for a better understanding of the physical mechanisms of skull fracture in accidental hits, falls, bicycle - motor vehicle \& car accidents and assaults. The performance and biofidelity of these models depend on the correct anatomical representation and material description of these structures. In literature, a strain energy criterion has been proposed to predict skull fractures. However, a broad range of values for this criterion has been reported. This study investigates if the impactor orientation, scalp thickness and material model of the skull could provide us with insight in the influencing factors of this criterion.

18 skull fracture experiments previously performed in our research group were reproduced in finite element simulations. Subject-specific skull geometries were derived from medical images and used to create high-quality finite element meshes. Based on local Hounsfield units, a subject-specific isotropic material model was assigned.

The subject-specific models were able to predict fractures who matched visually with the corresponding experimental fracture patterns and provided detailed fracture patterns. The sensitivity study showed that small variations in impactor positioning as well as variations of the local geometry (frontal-
\end{abstract}


temporal-occipital) strongly influenced the skull strain energy. Subject-specific modelling leads to a more accurate prediction of the force-displacement curve. The average error of the peak fracture force for all the 18 cases is 0.4190 for the subject-specific and 0.4538 for the homogeneous material model, for the displacement; 0.3368 versus 0.3844 . But it should be carefully interpreted as small variations in the computational model significantly influence the outcome.

\section{Keywords:}

Finite Element Modelling, Head Injury, Impact Biomechanics, Skull Fracture

\section{Introduction}

\subsection{Epidemiology}

Yearly, approximately 26000 people die and 1.3 million are injured due to road accidents in the European Union [1]. For young people between 15 and 29, road traffic injuries are the leading cause of death [2]. In Belgium, cyclists account for more than $20 \%$ of the serious injuries and more than $10 \%$ of the deaths in traffic [3]. Depreitere et al. investigated 86 victims of bicycle accidents and found an incidence rate of $86 \%$ for skull fractures [4]. The treatment and rehabilitation of patients with head injuries is often long and difficult, causing high socio-economic costs. These observations stimulate the need for research to determine the cause of injuries and to develop improved protective headgear.

\subsection{Skull Fracture Criteria}

Though numerous PMHS studies have investigated the mechanics and characteristics of skull fracture resulting from blunt head impacts $[4,5,6,7,8,9,10]$, a unified criterion for skull fracture is still under discussion. Gurdjian et al. [5] performed one of the first experimental studies. They concluded that linear skull fractures originate from tensile stresses caused by the inward bending of the skull due to the impact or the outward bending at a distance of the impact 
location [5]. It has been widely accepted that peak force cannot be the exclusive criterion for skull fracture [11], and the range of $50 \%$ risk of skull fracture is large $(1885$ - 12500 N) $[12,13]$. The Wayne State University Tolerance Curve (WSTC) indicates the role of duration of the acceleration and (force) pulse [14]. Yoganandan et al. was the first to study the influence of the load velocity on the fracture force and found that the critical force increased from a mean of 6.4 $\mathrm{kN}$ to a mean of $11.9 \mathrm{kN}$ with an impact velocity increasing from $0.002 \mathrm{~m} / \mathrm{s}$ to $7.0-8.0 \mathrm{~m} / \mathrm{s}$, while the energy to failure remained in the same range (mean 33.5 $\mathrm{J}$ to $28.0 \mathrm{~J}$ ) [8]. Yoganandan et al. proposed that the strain energy absorbed by the skull could be a good predictor for skull fractures. Such a criterion should be able to take into account all impact and structural aspects such as impact velocity, skull geometry and bone strength [8].

The Head Injury Criterion (HIC) was introduced by the National Highway Traffic Safety Administration (NHTSA), based on the work of Gadd et al. $[15,16]$. This criterion, widely adopted over the world, integrates the linear acceleration at the center of gravity of the human head over time. However, HIC has severe limitations as it does not take into account the angular accelerations. New criteria were introduced such as the GAMBIT and HIP (Head Impact Power) by Newman et al. [17, 18], which include the angular accelerations. These criteria are not directly dependent or based on injury mechanisms [19]. Vander Vorst et al. introduced the Skull Fracture Correlate (SFC) based upon post-mortem human subject (PMHS) tests, anatomical test device measurements and statistical analyses. The SFC is defined as the averaged acceleration over the HIC time interval [20, 21].

Our research group previously investigated the accuracy of an energy failure criterion for skull fracture with a double pendulum set-up in a series of experiments. Based on this new test set-up, described by Verschueren et al. [22] (developed by Van Lierde, Depreitere et al.), with intact unembalmed head specimens, Delye et al. found an energy failure level in the range of $22-24 \mathrm{~J}$ 
for dynamic frontal loading [9]. Monea et al. suggested an energy criterion in the range of 5 - $15 \mathrm{~J}$ for temporal impacts based on similar impact experiments as Delye et al. [23].

\subsection{Generic Finite Element (FE) Models for Skull Fracture}

The development of FE head models proved to be a very promising track for head trauma biomechanics [19], capturing the complex anatomical structures and material models, hence leading to the development of better defined head injury criteria and studies [16]. The Strasbourg University Finite Element Head Model (SUFEHM) has been extensively used to investigate skull fractures [24]. In recent improvements the skull bone is modelled as an anisotropic composite material which takes into account material damage with the Tsai-Wu criterion [25]. Different studies using the SUFEHM investigate the existence of an energy fracture criterion, defined as the maximum amount of internal strain energy absorbed by the deformable skull before fracture occurs. The energy threshold for $50 \%$ risk on skull fracture ranged from $453 \mathrm{~mJ}$ to $833 \mathrm{~mJ}[16,25,19]$. Asgharpour et al. reconstructed numerically with the SUFEHM, the head impact tests performed by Delye et al. and found an average skull strain energy of 5531 mJ when frontal skull fracture occurred. This is low compared to the PMHS experiments $[9,23]$, note that in these experiments the total absorbed energy of the PMHS head specimen is reported, while in the SUFEHM studies only the energy is reported for the skull. They stated that the results could be influenced by subject-specific geometries and a finer mesh could probably improve the accuracy of the prediction of fracture patterns [26].

\subsection{Subject-Specific Finite Element (FE) Model for Skull Fracture}

The advantage of a subject-specific head model compared with the generic FE head model is the geometric accuracy and subject-specific material properties of the skull. A disadvantage is the time consuming process of creating 
these subject-specific geometries and meshes. Kemmoku et al. suggested the use of a FE model with simplified skull bone geometry while maintaining the essential parts to study skull fracture patterns after direct impact on the skull. Fracture lines were identified as areas with high principal stresses [27]. The use of subject-specific models to investigate skull fracture is limited [28, 29], Huang et al. validated a single impact experiment using a subject-specific skull model. The skull was modelled as a three layer sandwich structure with homogeneous material parameters and the yield stress for cortical bone was used to simulate fracture [30]. However, a more biofidelic model of the human head is necessary to correctly predict the stress and strain behaviour during falls, accidents and assaults [?].

To our knowledge, no studies have been performed combining both a subjectspecific geometry and a subject-specific material model for the skull. This study reconstructs a relatively large number (18) of PMHS experiments from [23] and implements both a subject-specific skull geometry and a subject-specific material model for cranial bone based on Hounsfield units (HU). The goal is to investigate the influence of both the local geometry at the impact site and the material model on the internal skull strain energy and the prediction of the fracture patterns.

\section{Materials and Methods}

\subsection{Experimental Data}

Subject-specific FE models were created that mimicked experiments performed by Monea et al., details can be found in [23]. In short, impacts were successfully performed on / colorred18 intact human cadaver heads / colorblack (three frontal, five occipital and ten temporal). The set-up consisted of two pendulums (Figure 1), one used to mount the specimen and the other to strike the blow. The angle of the impact pendulum was altered to obtain impacts at 
different impact velocities. The position of the specimen on the first pendulum was changed to obtain impacts at the three different locations. The impact pendulum was constructed from steel (mass $=26.5 \mathrm{~kg}$, length $=146 \mathrm{~cm}$ ) and had a cylindrical impactor (diameter $=60 \mathrm{~mm}$ ) made out of aluminium at its end. The resulting impact force was measured by a force sensor which was connected to the impactor. Mass was added to the impactor to increase the likelihood of fracture. The pendulum connected to the specimen was made of aluminium $($ mass $=5.6 \mathrm{~kg}$, length $=128 \mathrm{~cm})$ and the specimens were connected to the pendulum using a polyester resin in the foramen magnum. To record the deformation of the specimen in the plane of impact, the relative displacement between the two pendulums was measured using a laser sensor. The strain energy was calculated by an integration of the measured force over the measured displacement. Experimental data was sampled at $65000 \mathrm{~Hz}$ and filtered using a low-pass Butterworth filter with a cut-off frequency of $4000 \mathrm{~Hz}$ to remove acquisition noise.The experiments were carried out at three different impact velocities: low $(3.27-3.87 \mathrm{~m} / \mathrm{s})$, intermediate $(4.12-4.74 \mathrm{~m} / \mathrm{s})$ and high velocities (5.40-5.92 m/s). Information of each specimen can be found in Appendix A, specimens where the experiment failed were not mentioned in this study. An overview of the experimental output, such as peak forces and strain energies is given in Appendix B.

\subsection{Finite Element Simulation of the Experiments}

\subsubsection{Subject-Specific Finite Element Head Models}

The subject-specific FE head models were created from medical images. High quality CT-scans ( $512 \times 512$ scanning matrix, slice thickness $=1 \mathrm{~mm}$, slice increment $=0.5 \mathrm{~mm}$, pixel size $=0.449 \mathrm{~mm}$ ) were obtained using a Siemens SOMATOM Sensation-64 CT scanner. These scans were acquired before and after the impact experiments performed in [23] to evaluate pre-existing fractures and resulting fractures from the impacts. Each CT-scan was imported in Mimics ${ }^{\mathrm{TM}}$ (Materialise, Leuven, Belgium) and the skull was segmented manually, complex 


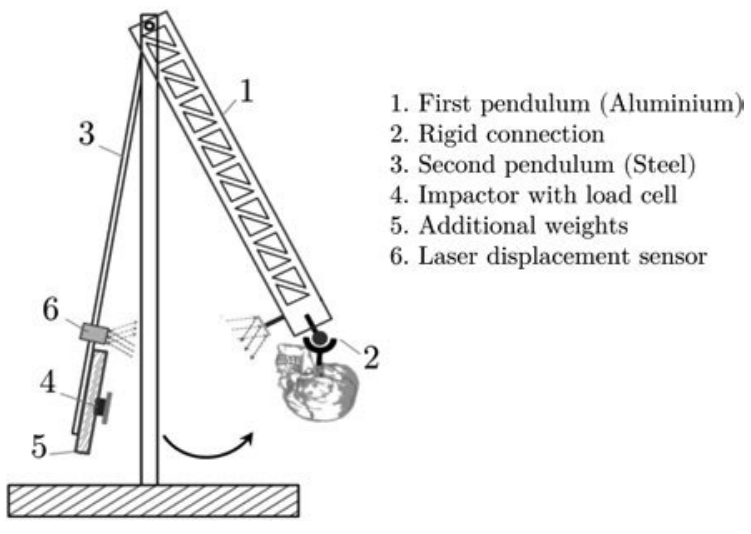

Figure 1: The schematic set-up with its components (adapted from [23]).

structures of the nasal conchae were omitted as well as the lower mandible, after which a $3 \mathrm{D}$ geometry was calculated. ANSA ${ }^{\mathrm{TM}}$ (BETA CAE Systems, Thessaloniki, Greece) was used to mesh the geometry with strict mesh quality criteria, see Table 1. A convergence study was performed on one FE head model, ranging from 40000 to 1.5 million quadratic tetrahedral elements (C3D10M). The maximum and minimum principal stress and strain at the location of interest (impact site) were evaluated for every simulation. At one million C3D10M elements the maximum and minimum principal stress and strain converged, additional mesh refinement did not affect the results. The average amount of elements along the thickness of the skull at the impact site was 5.66 for the frontal impacts, for the temporal site this was 3.70 and for the occipital site there were 5.60 elements on average.

Table 1: Quality criteria used to evaluate the surface and volume mesh in ANSA ${ }^{\mathrm{TM}}$.

\begin{tabular}{c|rr} 
& Surface Mesh & Volume mesh \\
\hline Aspect Ratio & 8 & 3 \\
Skewness & 0.4 & 0.7 \\
Jacobian & 0.7 & 0.7 \\
Average Length [mm] & 1.44 & 1.15
\end{tabular}

For each skull model two material models were implemented, a homoge- 
neous isotropic linear material and a subject-specific isotropic material based on Hounsfield units (HUs). The homogeneous model, identical to the validated FE model by Zhou et al. [31], used a Young's modulus of E $=8 \mathrm{GPa}$ and a density ranging from $3.67-4.70 \mathrm{~g} / \mathrm{cm}^{3}$. The material density was chosen such that the mass of the skull in the simulation equals the total mass of the corresponding human cadaver head. The material model was considered to be purely brittle and plastic material behaviour was not modelled $\left(\sigma_{\text {yield }}=\sigma_{u l t}\right)[32]$.

For the subject-specific material model, the local bone density was linked to local material properties which included material failure. First, the subjectspecific tissue density was based on the relationship between HUs and the measured bone mineral density as described by Wagner et al. [33]:

$$
\rho_{t}=\left[1-\left(\frac{\rho_{w}}{\rho_{i}}\right)\right] * \rho_{H A}+\left[R_{o} *\left(\rho_{o}-\rho_{w}\right)+\rho_{w}\right],
$$

where $\rho_{t}$ is the real tissue density in $\mathrm{g} / \mathrm{cm}^{3}, \rho_{w}$ is the water density in $\mathrm{g} / \mathrm{cm}^{3}, \rho_{i}$ is the inorganic density in $\mathrm{g} / \mathrm{cm}^{3}, \rho_{H A}$ is the measured bone mineral density in $\mathrm{gH} \mathrm{A} / \mathrm{cm}^{3}, R_{o}$ is the volume fraction of the organic constituent (dimensionless) and $\rho_{o}$ is the organic density in $\mathrm{g} / \mathrm{cm}^{3}$. When using the densities and organic fraction proposed by Martin et al. [34], this equation reduces to:

$$
\rho_{t}=0.6667 * \rho_{H A}+1.144
$$

Martin et al. combined the relationship between the calcium content and the Young's moduli of bone from Currey et al. [35] with equation 1 to obtain a link between the mineral density and the Young's modulus of bone:

$$
\log _{10}\left(E_{t}\right)=-8.58+4.05 * \log _{10} \frac{400}{1+\left(\frac{0.504}{\rho_{H A}}\right)},
$$

where $E_{t}$ is the tissue Young's modulus in GPa. This curve (Figure 2) describes the elastic behaviour of the skull bone in function of the tissue density. Bone is said to be fully mineralized at $1.2 \mathrm{gHA} / \mathrm{cm}^{3}$ [36]. Therefore, the curve was truncated at $1.2 \mathrm{gHA} / \mathrm{cm}^{3}$ and above this threshold, voxels received a value of $2.15 * 10^{4} \mathrm{MPa}$, as shown on Figure 2. Similarly, voxels with a very low bone 
mineral density $\left(0.2 \mathrm{gHA} / \mathrm{cm}^{3}\right)$ were assigned a constant low modulus of 550 $\mathrm{MPa}$, in order to avoid numerical problems during the FE simulations as a result of the very low stiffness of these volumes.

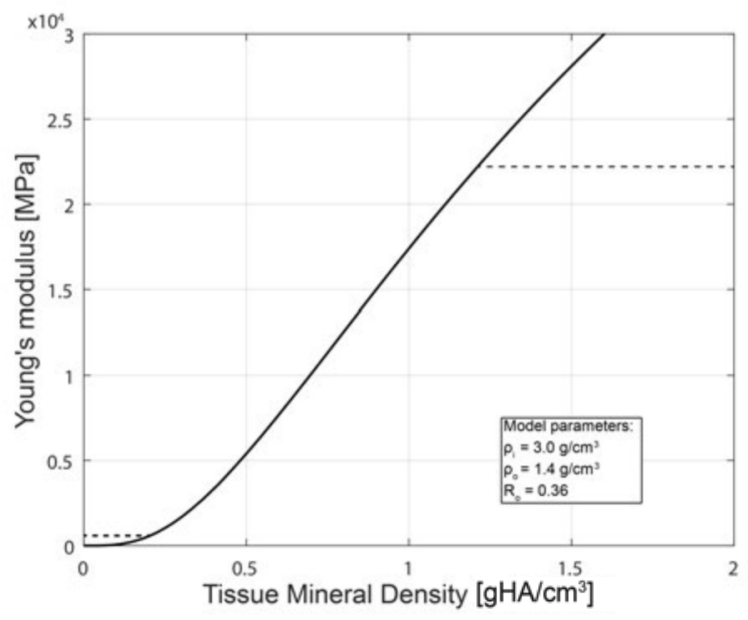

Figure 2: The elastic behaviour of skull bone is described by the relationship between tissue mineral density and Young's moduli. The curve is truncated at the lowest, from 0-0.2 $\mathrm{gHA} / \mathrm{cm}^{3}$, and highest densities, from $1.2 \mathrm{gHA} / \mathrm{cm}^{3}$, to avoid inaccurate results (dotted line).

Finally, the brittle behaviour of skull bone was modelled by interpolation of the ultimate tensile stress at lower bone mineral density, $30 \mathrm{MPa}$, and higher mineral bone density, $80 \mathrm{MPa}$, used in the KTH FE head model [37] based on the experimental studies of $[32,38,39]$. This model uses two materials, one for cortical and one for trabecular bone. The ultimate tensile stress was extrapolated for the different tissue mineral densities, as seen on Figure 3. The ultimate strain for all Young's moduli was assumed to be constant:

$$
\epsilon_{u l t}=\frac{\sigma_{u l t}}{E}=c,
$$

where $\epsilon_{u l t}$ is the ultimate strain, $\sigma_{u l t}$ is the ultimate strength of the material and $c$ is a constant. To quantify failure of the cranial bone, the Tensile Failure criterion in Abaqus was used, due to its compatibility with highly dynamic 
problems and its ability to remove failed elements from the mesh.

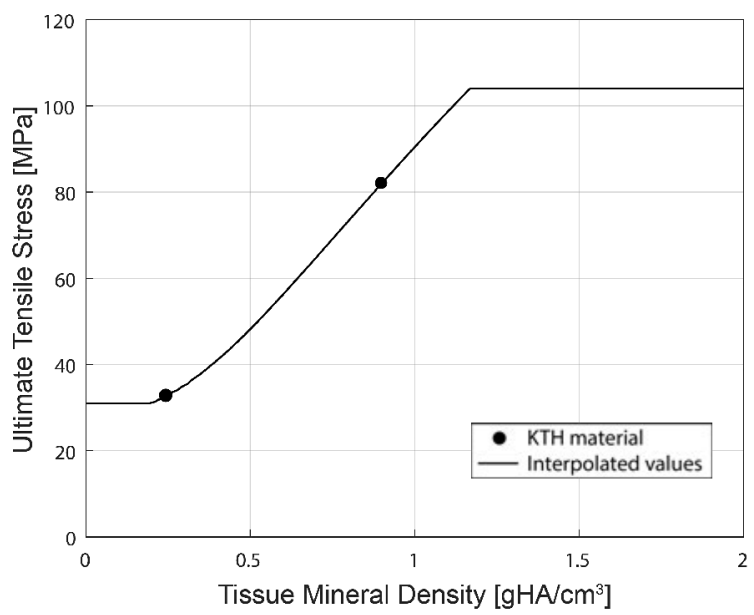

Figure 3: The ultimate tensile stress is extrapolated for different tissue mineral densities based on Young's moduli and tensile stresses of the KTH FE model. The ultimate strain at fracture is assumed to be constant.

The scalp layer was modelled as a soft homogeneous elastic material using the Young's modulus and Poisson's ratio found in both the KTH and SUFEHM models [25], [40]. The aluminium impactor was modelled as a homogeneous isotropic elastic material, using the Young's modulus for aluminium found in literature [41]. The mass of the impactor incorporated the additional masses present in the set-up. The material properties used in this study are summarized in Table 2.

Table 2: The material properties of the different parts used in the simulations.

\begin{tabular}{c|cccc} 
Part & Impactor & Scalp & \multicolumn{2}{c}{ Skull } \\
& & & Homogeneous & Subject-Specific \\
\hline Mass [kg] & 15 & $\approx 0$ & subject & subject \\
Young's Mod. [MPa] & 70000 & 16.70 & 8000 & $500-21500$ \\
Poisson's Ratio [-] & 0.33 & 0.42 & 0.22 & $0.22-0.24$ \\
Tensile Strength [MPa] & $/$ & $/$ & 43.44 & $30.94-103.97$ \\
Element Type & C3D8R & C3D8R & C3D10M & C3D10M
\end{tabular}




\subsubsection{Reconstruction of the Experiments}

The aforementioned successful experiments were reconstructed in Abaqus, whereby the set-up was simplified to shorten the calculation time. A parameter study showed that it was unnecessary to model the entire double pendulum system, as the additional inertia of the pendulums was negligible [42]. Hence, the set-up was reduced to the impactor and the head specimen. The skull of each specimen was modelled, as well as a simplified subject-specific scalp layer that was added as a segment to the impactor, as done by Asgharpour et al [26]. The scalp thickness, not uniform over the head, was measured by Monea et al. for every specimen [23]. The average subject-specific scalp thickness at the location of impact was used for the implementation of the segment on the impactor. The impactor was assigned the same geometry and mass as in the experiments.

The impactor was positioned as documented in the experimental data. The impact velocity recorded in the experimental data was applied to the impactor. Impactor and skull were allowed to move in the plane of motion, but rotations and translations perpendicular to this plane were constrained. These boundary conditions simulate the rigid connection between the pendulum and the skull

. In the experiments the bottom of the skull was attached to the pendulum in the foramen magnum, this attachment method was mimicked in the FE simulation. The contact between the scalp layer on the impactor and the skull was defined as a general contact and a contact pair was assigned. Contact between the elements of the skull was also defined as a general contact in order to model the behaviour of the skull after fracture.

The total absorbed strain energy until fracture was calculated using the contact force between the scalp layer and skull as well as the impactor displacement. Additionally, the strain energy absorbed by the skull and scalp were evaluated separately. The contact area and the damage state of each element was included in the output. The artificial strain energy, in Abaqus the energy to prevent un- 
controlled deformation of elements by adding a virtual stiffness to the critical elements, of the scalp layer was tracked and monitored. This value should be under $5 \%$ of the total energy in the scalp layer to obtain reliable results and detect hourglassing [43]. Statistical analysis of the output data was performed in MATLAB ${ }^{\mathrm{TM}}$ 2017a (The Mathworks).

\subsubsection{Sensitivity Study}

The sensitivity of the impactor orientation and the scalp layer thickness was investigated for one case of the frontal, temporal and occipital impact site (respectively ID 2, ID 11 and ID 19 in Appendix A and Appendix B).

\section{Impactor Orientation}

The smoother surface of the frontal impact allowed for different impactor orientations without changing the impacted location on the skull. The rotation angle $\alpha_{\text {rot }}$ ranged from 0 to 10 degrees, the translations $\left(d_{\text {trans }}\right)$ ranged from 0 to $18 \mathrm{~mm}$ to maintain the original impact location (see Figure 4). The temporal impact had a sharp impact angle at the temporal site of the skull. The impactor was oriented to a new position more aligned with the local bone surface. The impactor was rotated 15 degrees in the transverse plane, 8 degrees in the sagittal plane and translated $20 \mathrm{~mm}$. The occipital impact location was characterised by a local protrusion in the skull bone. By applying a rotation and a translation the protrusion is avoided (see Figure 4).

\section{Scalp Variation}

The scalp thickness was modelled for every impact site with three different values, (1) the original documented scalp thickness [23], (2) half the original and (3) twice the original scalp thickness (see Table 3). In these nine cases (three

for each impact site), the scalp was defined as an extra layer that fits the skull geometry perfectly, as depicted on Figure 5. The scalp is created on the skull, only for the area into contact with the impactor. The outer surface of the scalp 


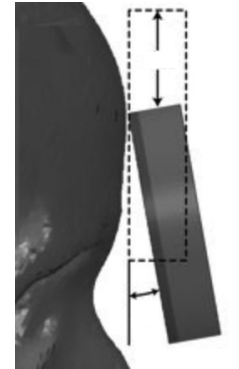

Frontal

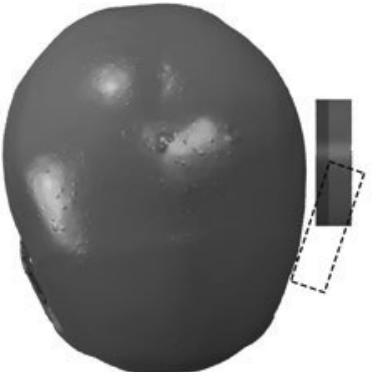

Temporal

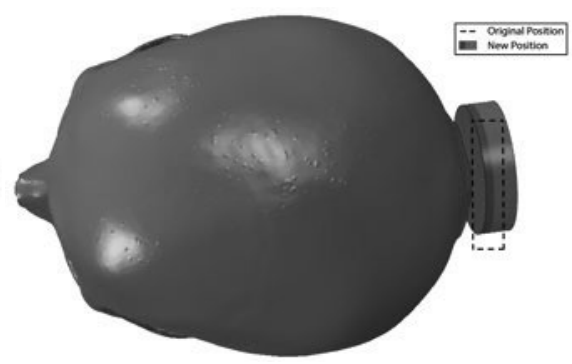

Occipital

Figure 4: The impactor is rotated and translated for the frontal, temporal and occipital impact site whilst maintaining the impact location. The original position is delineated in the dashed line.

was rigidly connected to one central point on the impactor, see Figure 5. This was done to exclude the influence of impactor orientation on the outcome of the simulation for this sensitivity analysis of the scalp thickness.

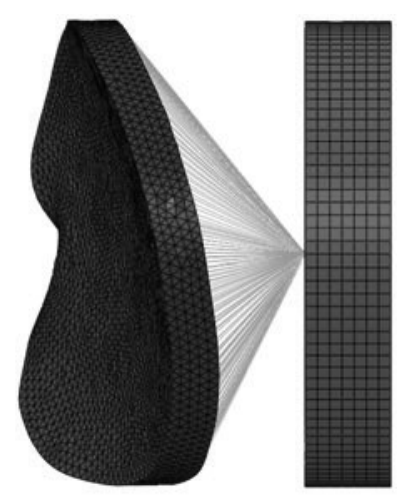

Figure 5: The scalp is modelled to fit the skull geometry perfectly. The scalp is rigidly coupled to one central node on the impactor. The impactor is modelled as a rigid body.

\section{Results}

\subsection{Head Impact Simulations}

An overview of the results of the 18 impact experiments can be found in Appendix B. Figure 6 shows typical force-displacement curves for an experi- 
Table 3: Table summarising the modelled scalp thicknesses. The contact area increases for locations with increased curvature such as the temporal bone.

\begin{tabular}{cccc} 
Skull ID & Location & Contact Area $\left[\mathrm{mm}^{2}\right]$ & $\begin{array}{c}\text { Scalp Thickness }[\mathrm{mm}] \\
\text { (Half/Original/Double) }\end{array}$ \\
\hline 2 & Frontal & 2966 & $1.26 / 2.52 / 5.04$ \\
11 & Temporal & 3027 & $3.07 / 6.13 / 12.26$ \\
19 & Occipital & 2994 & $1.89 / 3.77 / 7.54$
\end{tabular}

mental and a simulated impact from simulation ID 2. The three curves show great similarity in the initial region, however after a certain displacement the experimental curve rises more gradually. The peak of the simulated curve of the subject-specific material model, which resembles the peak fracture force, measures $10383 \mathrm{~N}$, for the homogeneous material model it measures $8025 \mathrm{~N}$, while the experimentally measured force is $9870 \mathrm{~N}$. The simulated force declines rapidly once fracture occurs whereas the experimental curve declines more slowly. This behaviour is present for both the homogeneous and subject-specific bone properties.

The mean peak fracture force values in Table B.7 in Appendix B show that the accuracy of the subject-specific material model is higher than that of the homogeneous material model (error on mean $20 \%$ and $38 \%$ respectively). Table 4 shows the average error of the simulated peak fracture force, displacement and fracture strain energy for the homogeneous and subject-specific material model for all the 18 cases (Total) and for each impact site (Frontal, Temporal, Occipital). The error per case is calculated as; Error $_{i}=\sqrt{\left(\operatorname{Var}_{\text {exp }, i}-\operatorname{Var}_{\operatorname{sim}, i}\right)^{2}} / \operatorname{Var}_{\text {exp }, i}$ , $\operatorname{Var}_{e x p, i}$ is the experimental variable for skull ID $i$ (experimental peak fracture force, experimental displacement or experimental fracture strain energy), $V a r_{\text {sim }, i}$ is the simulated corresponding variable for the homogeneous or subjectspecific material model (simulated peak fracture force, simulated displacement or simulated fracture strain energy). Appendix $\mathrm{C}$ gives an overview of the error per case for the homogeneous and subject-specific material model for the peak fracture force, the displacement and the fracture strain energy. 


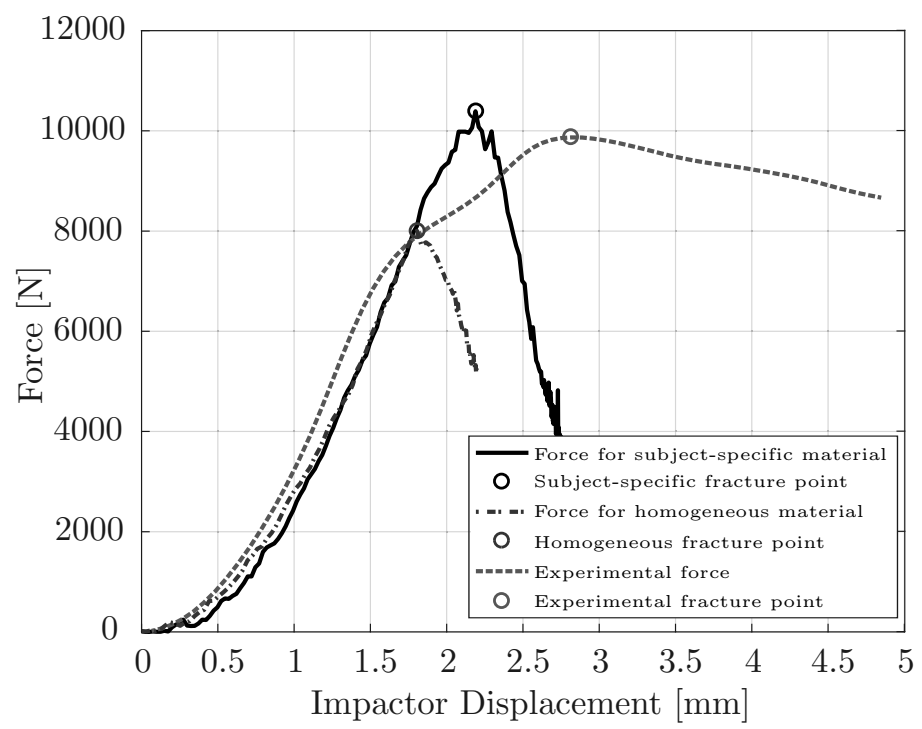

Figure 6: For skull ID 2, the simulated force-displacement curve for the homogeneous as the subject-specific material model follows the experimental data accurately, whereas it does not predict the more gradual phase which influences the accuracy of the calculated strain energy.

To assess if the homogeneous and subject-specific material model predict a significant different result, a paired t-test is performed (the data is normal distributed, Shapiro-Wilk p-value $>0.05$ ). For all the impacts (Total), the peak fracture force and fracture strain energy show a significant difference between the two material models. For the frontal impacts, the displacement and fracture strain energy show a significant difference $(\mathrm{p}$-value $<0.05)$. The average error of the peak fracture force of the subject-specific material model is larger if only the occipital cases are taken into account. For the displacement, the subject-specific material model shows a lower average error for all the impacts (Total) and the frontal impacts. The average error of the fracture strain energy for the subject-specific material model is only lower than the homogeneous material model for the occipital impacts. The average error for the peak fracture force is the lowest for the subject-specific material model at the frontal site. For the displacement, it is the lowest for the subject-specific material model at 
the temporal site. While for the fracture strain energy, the average error is the lowest for the subject-specific material model at the occipital site. The mean peak fracture force for the experiments is the highest for the occipital impacts followed by the frontal and temporal impacts, for the subject-specific as well as the homogeneous material model, the mean peak fracture force is the highest for the frontal, followed by the occipital and temporal impacts (Appendix B).

Table 4: Average error of the peak fracture force, the displacement and the fracture strain energy for all the 18 cases (Total) and for each impact site (Frontal, Temporal, Occipital).

\begin{tabular}{c|cccccc} 
Error & \multicolumn{2}{|c}{ Peak Force } & \multicolumn{2}{c}{ Displacement } & \multicolumn{2}{c}{ Fracture Strain Energy } \\
& Homogeneous & Subject-Specific & Homogeneous & Subject-Specific & Homogeneous & Subject-Specific \\
\hline Total & 0.4538 & 0.4190 & 0.3844 & 0.3368 & 0.5806 & 0.6398 \\
Frontal & 0.3711 & 0.3029 & 0.5006 & 0.5158 & 0.5946 & 0.6719 \\
Temporal & 0.5025 & 0.4310 & 0.3779 & 0.2724 & 0.6134 & 0.7673 \\
Occipital & 0.4062 & 0.4646 & 0.3278 & 0.3582 & 0.5065 & 0.3656
\end{tabular}

The coefficient of variation for the frontal, temporal and occipital locations is $0.29,0.79$ and 0.50 respectively for the models with subject-specific properties. There is a strong correlation between the absorbed strain energy and the contact area at fracture, as shown on Figure 7, as well as the skull bone thickness (Pearson's correlation $r=0.77$ and $r=0.45$ respectively, $p<0.05$ for models with the subject-specific material). The strain energy absorbed by the skull only represents $28 \%$ of the total strain energy at fracture.

The resulting fracture lines are different for both material models, as shown in Figure 8. Typical fracture patterns are distinguishable for each impact location (frontal, temporal and occipital). For the frontal impact, the subjectspecific material model predicts the points of initiation near the orbita more accurately and the progression of the fracture line is also in better agreement with the experimental data than the homogeneous material model. The temporal fracture patterns are strongly dependent on the exact impact location. Multiple fractures extend from nearby the point of impact towards the sphenoid bone and the inferior part of the occipital bone. In some cases additional 


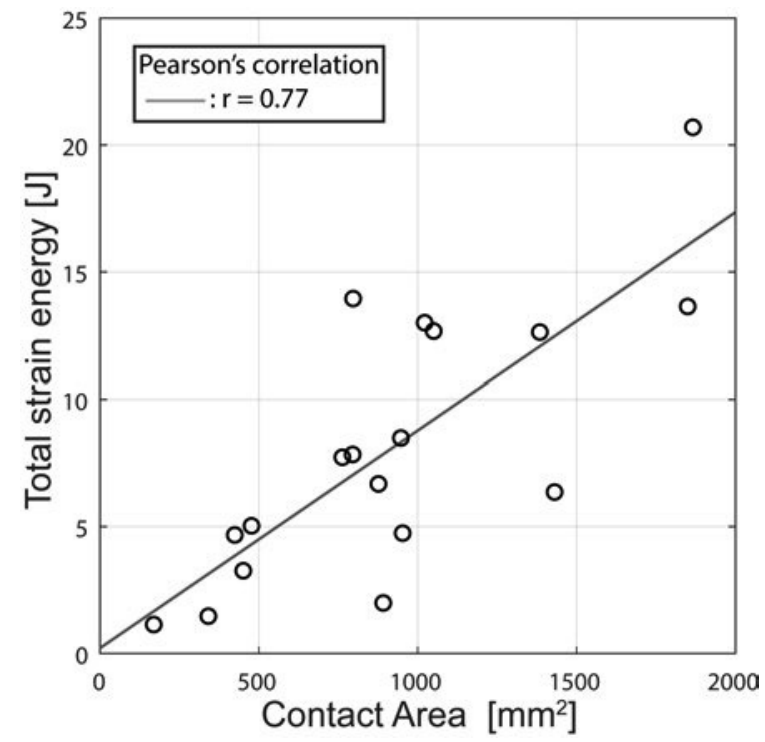

Figure 7: The total strain energy is strongly correlated with the contact area at the moment of fracture.

fractures towards the posterior and superior side of the skull are seen. The subject-specific material model is able to predict the fractures that extend to the sphenoid and zygomatic bone. Occipital impacts lead to severe and complex fracture patterns, originating from the lambdoid suture and propagating centrifugally towards the impact location. The fracture patterns closely follow the lambdoid and sagittal sutures, depicted on Figure 8. The subject-specific material model matched visually the centrifugally propagating fracture pattern at the parietal and occipital bone as well as the fractures at the suture lines.

\subsection{Sensitivity Study}

\section{Impactor Orientation}

For each orientation of the impactor, the contact area is different. For the frontal impacts, nine different impactor positions were simulated. The contact area is strongly correlated with peak force, skull strain energy and scalp strain energy (Pearson: $r=0.97, r=0.93$ and $r=0.995, p<0.05$ for all). Figure 9 


\section{HomogeneOUs}

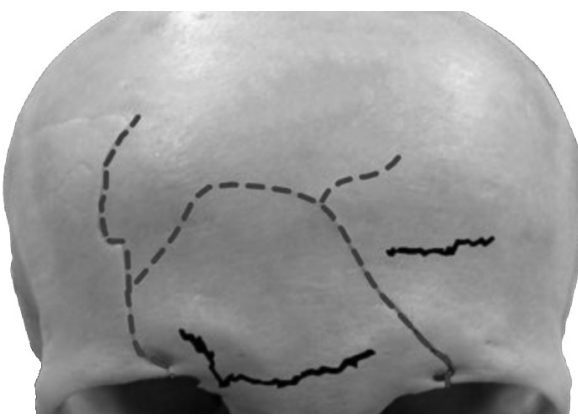

Frontal Impact

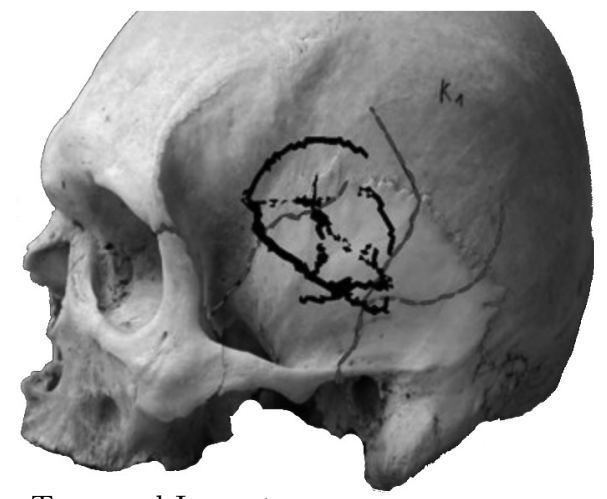

Temporal Impact

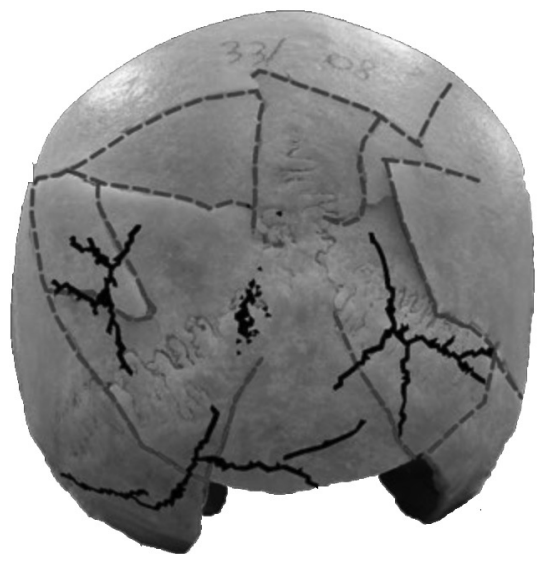

Occipital Impact
SuBJECT-SpecifiC
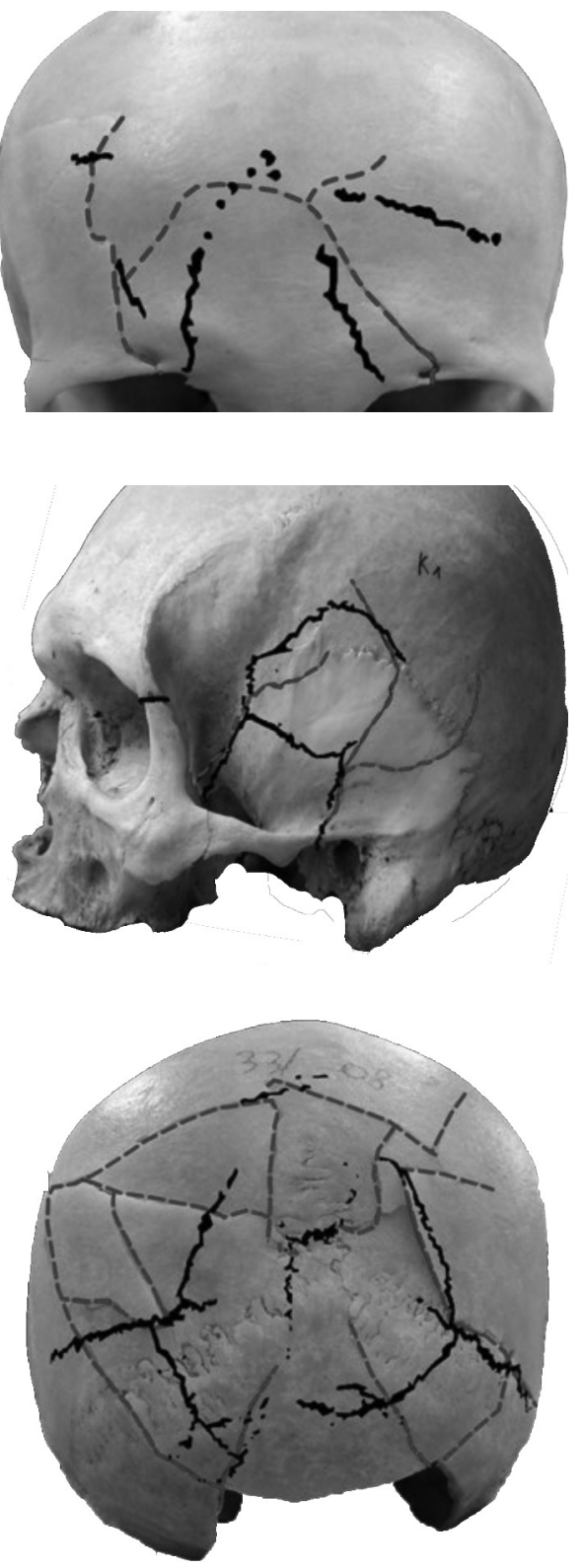

Figure 8: Comparison between the two material models, showing the simulated fracture lines (black) imposed on a picture of the skull post-impact with the experimental fracture lines (dotted red). The subject-specific material model is able to capture the fracture lines visually more accurate for all impacts. For the frontal impact, the point of initation is near the orbita, extending to the frontal skull bone (ID 2). Impact on the temporal site result in fractures extending from the impact site to the orbita (ID 11). Occipital impacts lead to complex fractures surrounding the impact area and extending anteriorly (ID 19). 
shares the correlation of $r=0.995$ between contact area and skull strain energy.

The results for the temporal (ID 11) and occipital (ID 19) case are summarized in Table 5. Both impacts show an increase in skull strain energy if the contact area increases, identical to altered frontal impacts. The contact area of the new impactor positions is increased in comparison with the original position. An increase in absorbed energy in the scalp layer and skull is seen for the new impactor positions.

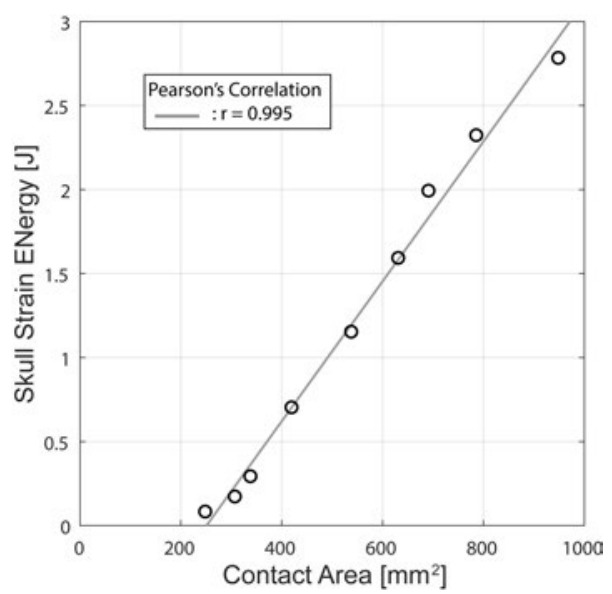

Figure 9: Nine simulated frontal impacts on a single specimen (ID 2) with a different impactor orientation but identical impact location, show an extremely strong correlation between contact area and skull strain energy.

Table 5: Results of the temporal (ID 11) and occipital (ID 19) simulations with altered impactor orientation (altered) and the impactor positioned as in the experimental data (original).

\begin{tabular}{ccccc} 
Orientation & Force $[N]$ & Contact Area $\left[\mathrm{mm}^{2}\right]$ & Scalp Energy $[J]$ & Skull Energy $[J]$ \\
\hline Temporal & & & & \\
Original & 1747.48 & 343 & 1.18 & 0.18 \\
Altered & 5357.61 & 884 & 3.15 & 1.32 \\
Occipital & & & & \\
Original & 5809.25 & 479 & 3.97 & 0.42 \\
Altered & 14774.51 & 1035 & 9.27 & 3.47
\end{tabular}




\section{Scalp Variation}

A higher scalp and skull strain energy is seen when the scalp is modelled to fit the skull geometry perfectly instead of the added segment to the impactor, see Figure 10, Appendix B and Appendix D. The contact area of the simulations with the scalp modelled to fit the skull geometry, increases $320 \%, 880 \%$ and $670 \%$ for the frontal, temporal and occipital case in comparison with the scalp as extra layer added to the impactor. The skull strain energy increases significantly for each specimen with the new scalp implementation $(210 \%, 1980$ $\%$ and $2260 \%$ for the frontal, temporal and occipital cases respectively). The scalp strain energy increases significantly for thicker scalp layers, as seen on Figure 10. The strain energy absorbed by the skull before fracture decreases with an increasing scalp layer.

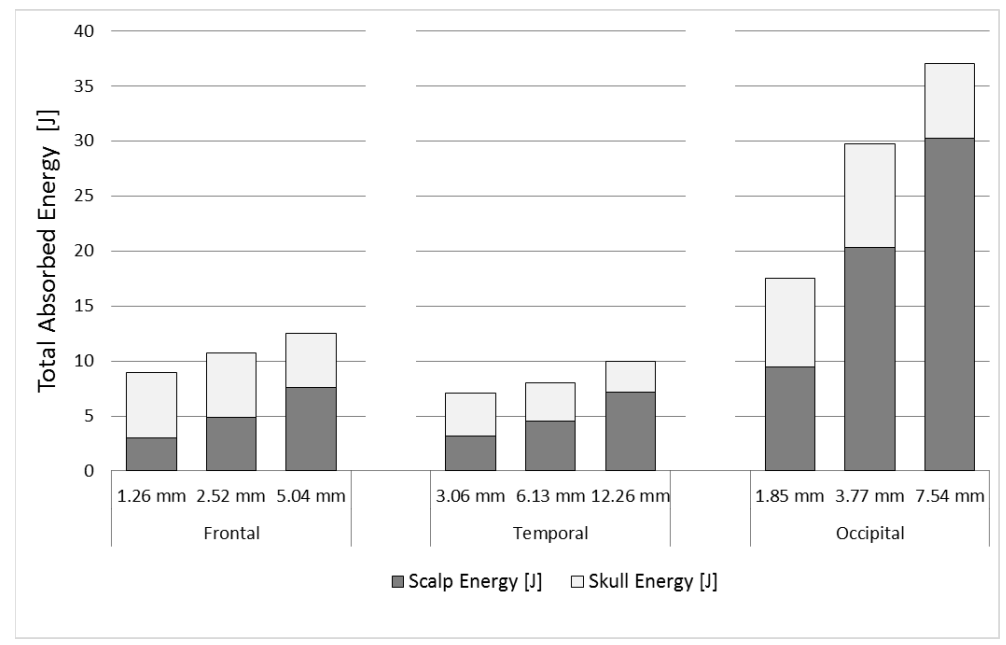

Figure 10: Bar graph showing the scalp and skull strain energy of the simulations with half, original and double scalp thicknesses for the frontal (ID 2), temporal (ID 11) and occipital (ID 19) cases. The absorbed scalp energy increases significantly for thicker scalps, so does the total absorbed energy. 


\section{Discussion}

\subsection{Head Impact Simulations}

The present study reconstructed 18 experimental impacts with finite element simulations using subject-specific geometry and two different material models. Models using the subject-specific material were able to predict the peak fracture force with higher accuracy than the models with homogeneous material parameters. Asgharpour et al. found a mean absolute percentage error between the experimental and simulated peak force value equal to $45 \%$ [26]. Our simulations with the subject-specific material model are able to simulate the frontal and temporal impacts with a mean absolute percentage error equal to $30 \%$ or $40 \%$ when the occipital impacts are included. The average error of the peak fracture force of the subject-specific material model is the lowest for the frontal cases, higher for the temporal and the highest for the occipital. The accuracy of the prediction strongly depends on the simulated case. For 11 of the 18 cases the prediction error decreases for the experimental peak fracture force when switched from a homogeneous to a subject-specific material model. For the displacement, the prediction error decreases for 13 of the 18 cases and 12 of the 18 cases for the fracture strain energy. The subject-specific material model increases the accuracy in $61 \%$ - $72 \%$ of the simulated cases. These differences between homogeneous and subject-specific models can be attributed to the assignment of local bone properties based on HUs. The subject-specific models are thereby able to represent the local bone architecture more accurately, this includes the cranial sutures and diploë layer of the skull. The effect of these local bone properties is strongly dependent on the exact impact location.

The force-displacement curve (Figure 6) indicates that the models used in this study do not predict the post-fracture behaviour precisely. Although the failure model accurately predicts the fracture initiation point, it does not take into account the required fracture energy. Consequently the post-fracture results should be interpreted with care. The fracture lines propagate rapidly through 
the bone based on the failure stresses, resulting in a steep drop in the measured contact force. This causes the model to underestimate the impactor displacement, resulting in a low predicted absorbed strain energy in the specimen. A second factor contributing to the unreliability of the post-fracture results, is that the intra-cranial tissues are not included into the model. Results pre-fracture until peak fracture force is reliable, as shown on Figure 6.

Multiple studies have used FE models to validate the existence of an energy criterion based on the skull strain energy. Marjoux et al. found a $50 \%$ probability value for skull fractures above $0.833 \mathrm{~J}$, but strain fracture energy levels ranged from 0.4 to $8.8 \mathrm{~J}$ [16]. Sahoo et al. found values ranging from 0.38 to $1.19 \mathrm{~J}$ for temporo-parietal impacts [25]. In a later study, the internal skull energy in 85 simulations based on 15 experiments and 70 reconstructed head trauma cases, ranged from 0.36 - $1.48 \mathrm{~J}$ [19]. The FE model of Sahoo et al. was validated with 86 lateral drop test on 17 PMHS specimens. A mean of 5 successive tests per PMHS specimen were performed. Monea et al. suggested a energy criterion in the range of 5 - $15 \mathrm{~J}$ for temporal impacts [23]. These studies $[16,19,23,25]$ report a large range of strain energy for the temporal impacts. In our FE study, the temporal skull fracture energy ranges from 0.18 to 3.91 $\mathrm{J}$, which is in line with the values found in literature (Figure 11). The large amount of energy absorbed by the scalp layer (72\%) suggests that the importance of the scalp layer should not be underestimated, see Figure 10. Influence of the scalp layer on the total strain energy should be further investigated.

This study is able to confirm the high variation in strain energy found for the temporal impact site compared to the frontal and occipital regions. This behaviour was also found experimentally during the frontal and temporal impacts by Delye et al. and Monea et al. [9], [23]. The strain energy values are strongly correlated with the contact area and the skull thickness near the impact. The strain energy metrics do not incorporate these parameters appropriately. Furthermore, the strain energy absorbed by the scalp dominates the 


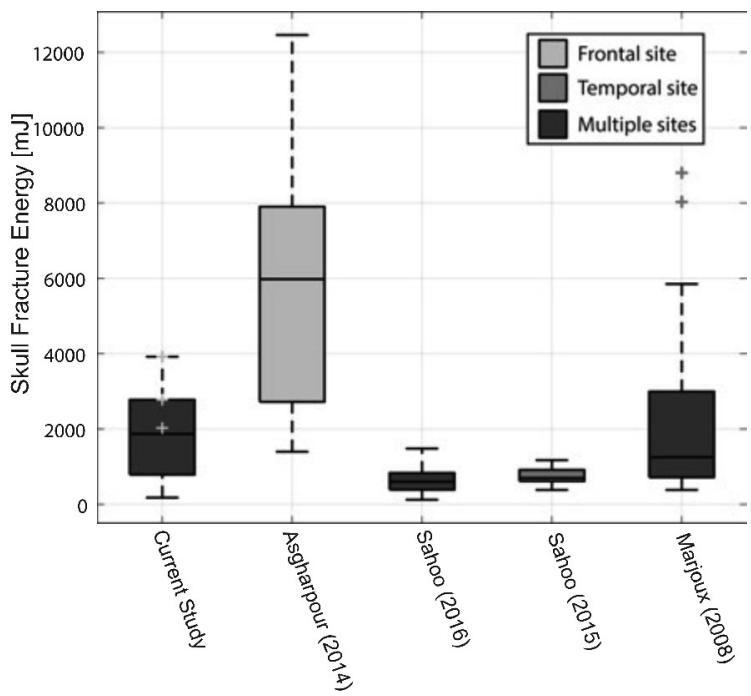

Figure 11: The skull strain energy is investigated in numerous studies using the SUFEHM. The values found in these studies are in agreement with the values found in literature, especially the data from Marjoux et al. The study by Asgharpour et al. which investigated frontal impacts is also in agreement, as the frontal impacts are in the whiskers of the boxplot (light-blue crosses). (Data estimated from [16], [19], [25], [26]). 
total strain energy found during these experiments, which corresponds to the results of experiments on skull specimens [22]. The importance of the contact area, which is influenced by the skull geometry emphasizes the importance of accurate FE model geometry and impactor positioning.

The skull of the FE model, developed by Sahoo et al. is implemented as a composite structure with a thickness of $7 \mathrm{~mm}$ (two cortical layers of $2 \mathrm{~mm}$ and a diploë of $3 \mathrm{~mm}$ ) [19, 25], however the skull thickness at the temporo-parietal side is the thinnest part of the skull with a mean thickness of $4 \mathrm{~mm}[44,45]$. In our FE study, is the similarity between the simulated and experimental fracture patterns higher than other FE studies due to the large number of elements in the FE mesh and a refined geometric subject-specific representation of the skull. The resulting fracture patterns of the subject-specific material model matched better quantitatively with the experimental fracture patterns than the homogeneous material model (Figure 8). High-speed camera footage could not be used to compare the origin of the fracture lines, due to the use of intact human head specimens. However, the locations of the fracture origins and patterns from the subject-specific FE models are in agreement with findings of other experimental studies $[46,22,9,47]$. The subject-specific material model is able to take into account the local bone densities and the errors caused by the partial volume effect during the segmentation of the skull. This error increases for thin structures such as the bones of the orbita. The homogeneous material model overestimates the strength of these locations when compared to the material assigned by the subject-specific material, which causes different fracture initiation points.

\subsection{Sensitivity Study}

The influence of the impactor position showed that the skull fracture energy criterion as proposed in literature is extremely sensitive to the contact area. Although the impactor is positioned based on the available data, slight deviations of the actual position during the experiment can greatly influence the outcome. For the frontal impact an almost perfectly linear relation is found between the 
contact area and skull strain energy. The geometry of the temporal and occipital areas is more complex, such that a different impactor position would result in a different impact site. A perfect alignment of the flat impactor with the irregular temporal bone surface was impossible. Identical difficulties were encountered at the occipital site, due to the external occipital protuberance. The contact area is identified as a key influencer for the skull strain energy. Generic FE head models, characterised by their smoothed anatomical representation, represent an average human head and use a coarse mesh when compared to subject-specific models. This will smooth out local deformations and stresses, resulting in less variability in the results, creating a less biofidelic skull strain energy criterion.

An increase in scalp thickness showed a significant increase in scalp strain energy and in total strain energy but a decrease in absorbed skull strain energy. A higher scalp thickness requires a larger displacement of the impactor before the full impactor load is transferred. However, the increase in scalp energy or increased displacement is not linearly related to the increase in scalp thickness. The decrease in skull strain energy with a higher scalp thickness is also found during the experimental tests [23]. The contact area was significantly larger than in previous original simulations due to the different implementation of the scalp.

\section{Study Limitations and Future Work}

Current study limitations include: firstly, the subject-specific material properties have to be validated with additional dynamic experiments which can be reconstructed with FE simulations to refine the parameter selection and allow for more accurate subject-specific assignment of material properties. Secondly, different failure models should be tested. The current Tensile Failure model gives satisfactory results given its simplicity, but its performance should be compared against more advanced failure models such as the Tsai-Wu criterion 
including the required fracture propagation energy. Thirdly, the scalp layer is influencing the impact characteristics and should be modelled as close as possible to reality. The scalp was implemented as done by Asgharpour et al. [26]. While this approach is convenient to model a large number of experiments, it can lead to inaccuracies. Individual segmentation of the scalp layers and defining a new interface between skull and scalp layer could estimate the scalp strain energy and contact area more accurately. The scalp implementation could be improved further using an anisotropic hyper-elastic material model which better describes the material properties of human scalp tissue. fourthly, the biofidelity of the model can be improved when the intra-cranial skull contents are included, resulting in a more accurate description of the post-fracture behaviour and fracture line propagation. Ongoing experimental work (data not published) of the HEADS-ITN will contribute to a biofidelic material model of the human scalp [48]. They reported that the scalp is an important factor in impact kinematics $[49,50]$. Finally, the robustness of the statistical analysis in this study is hampered by the limited number of data points available for the frontal and occipital impacts. Additional future experiments with accurate impactor positioning will increase the validity of $\mathrm{FE}$ head models that incorporate inter subjective differences.

Generic FE head models have a simplification of the exact anatomy of the human head, in which often not all the anatomical features are present. The skull geometry of these models is based on the Visible Human Database $[51,52,53,54]$, a CT-scan of a human (male) adult head $[55,24,56]$ or a representation of a $50^{\text {th }}$ percentile male head $[57,58]$. In these FE models, age, gender and head morphology is not taken into account. These generic models could benefit from age- and gender-based bone properties from regression equations, since cortical bone thickness changes with age and sex [59].

Sahoo et al. report the use of 86 lateral impacts on 17 PMHS specimens [19] for the validation of the FEM. However, due to the multiple impacts on the same 
PMHS specimen, microfractures could have existed in the skull of the PMHS before a fracture was detected, increasing the uncertainty of the results of the PMHS experiments. They used 70 head trauma cases collected from different pedestrian accident databases [19]. The use of accident reconstruction data for simulation of skull fractures could be a major limitation as the reliability of the replication of pedestrian accidents reported an error of $4-18 \%$ in the velocity measurements [60].

The use of subject-specific FE head models, which are manually segmented from medical images will always be limited. These models are extremely time consuming to model due to the complex segmentation of the $\mathrm{CT}$ images and the segmentation of soft tissues from MRI images. Calculation time of subjectspecific FE head models will be higher than generic head models due to the amount of elements used to cover the complex geometry.

\section{Conclusion}

This study investigated the validity of an energy based skull fracture criterion with subject-specific FE head models. 18 different experimental impacts were reconstructed and each impact was simulated with a homogeneous material model as well as a subject-specific model based on local bone densities. The models using the subject-specific material model predicted the moment of fracture with a higher accuracy than the homogeneous material model. Furthermore, these models have the ability to predict the fracture lines with, to the authors knowledge, unprecedented precision. However, the modelling of the post-fracture behaviour is currently not satisfactory and should be improved upon. The findings in this study identified influencing factors on the skull strain energy such as contact area, scalp thickness and impactor positioning. The energy criterion is unable to take into account the effect of differences in geometry and bone properties. These results strongly invalidate the existence 
of an energy-based fracture criterion. We concluded that subject-specific modelling leads to a more accurate prediction of the force-displacement curve but it should be carefully interpreted as small variations in the computational model significantly influences the results.

\section{Acknowledgements}

This research was funded by the Materialise Chair for image based, patient specific biomechanics, a FWO research project (G.0C67.13) and a postdoctoral fellowship of the Research Foundation Flanders (FWO) (PDO/012).

\section{References}

\section{References}

[1] The European Commission, Traffic Safety Basis Facts on Main Figures, Tech. rep., Directorate General for Transport, European Commision (2016).

[2] World Health Organization, Road Traffic Injuries Fact Sheet, Tech. rep. (2016).

[3] AD Statistiek - Statistics Belgium, Verkeer en vervoer - Verkeersongevallen, Tech. rep. (2016).

[4] B. Depreitere, C. Van Lierde, S. Maene, C. Plets, J. Vander Sloten, R. Van Audekercke, G. Van Der Perre, J. Goffin, Bicycle-related head injury : a study of 86 cases, Accident Analysis and Prevention 36 (4) (2004) 561-567. doi:10.1016/S0001-4575(03)00062-9.

[5] E. Gurdjian, J. E. Webster, H. Lissner, The Mechanism of Skull Fracture, Journal of Neurosurgery 7 (2) (1949) 106-114. 
[6] A. Nahum, J. Gatts, C. Gadd, J. Danforth, Impact Tolerance of the Skull and Face, in: Proceedings of the 12th Stapp Car Crash Conference, SAE International, Detroit, Michigan, USA, 1968. doi:10.4271/680785.

[7] A. Nahum, R. Smith, C. Ward, Intracranial Pressure Dynamics During Head Impacts, Tech. rep., SAE Technical Paper (1977). doi:10.4271/ 770922 .

[8] N. Yoganandan, F. A. Pintar, A. J. Sances, P. R. Walsh, C. L. Ewing, D. J. Thomas, R. G. Snyder, Biomechanics of Skull Fracture, Journal of Neurotrauma 12 (4) (1995) 659-668.

[9] H. Delye, P. Verschueren, B. Depreitere, I. Verpoest, D. Berckmans, J. Vander Sloten, G. Van der Perre, J. Goffin, Biomechanics of Frontal Skull Fracture, Journal of Neurotrauma 24 (10) (2007) 1576-1586. doi: $10.1089 /$ neu. 2007.0283 .

[10] D. Allsop, Skull and Facial Bone Trauma: Experimental Aspects, in: A. Nahum, J. Melvin (Eds.), Accidental Injury, Springer New York, 1993, pp. $247-267$.

[11] B. Depreitere, A Rational Approach to Pedal Cyclist Head Protection, Phd thesis, KU Leuven (2004).

[12] J. Cormier, S. Manoogian, J. Biplinghoff, S. Rowson, A. Santago, C. Mcnally, S. Duma, J. Bolte, The Tolerance of the Frontal Bone to Blunt Impact, Journal of Biomechanical Engineering 133 (2) (2011) 1-7. doi: $10.1115 / 1.4003312$.

[13] D. L. Allsop, T. R. Perl, C. Y. Warner, Force/deflection and fracture characteristics of the temporo-parietal region of the human head, SAE (Society of Automotive Engineers) Transactions 100 (6) (1991) 2009-2018.

[14] H. R. Lissner, M. Lebow, F. G. Evans, Experimental studies on the relation between acceleration and intracranial pressure changes in man, Surgery, gynecology \& obstetrics 111 (1960) 329. 
[15] C. W. Gadd, Use of a weighted-impulse criterion for estimating injury hazard, in: Proc. of the 10th Stapp Car Crash Conference, 1966. doi: $10.4271 / 660793$.

[16] D. Marjoux, D. Baumgartner, C. Deck, R. Willinger, Head injury prediction capability of the HIC, HIP , SIMon and ULP criteria, Accident Analysis and Prevention 40 (3) (2008) 1135-1148. doi:10.1016/j.aap.2007.12. 006.

[17] J. A. Newman, a Generalized Acceleration Model for Brain Injury Threshold (Gambit), Proceedings of IRCOBI Conference (1986).

[18] J. A. Newman, N. Shewchenko, E. Welbourne, A proposed new biomechanical head injury assessment function - the maximum power index., Stapp car crash journal 44 (2000) 215-247.

[19] D. Sahoo, C. Deck, N. Yoganandan, R. Willinger, Development of skull fracture criterion based on real-world head trauma simulations using fi nite element head model, Journal of the Mechanical Behavior of Biomedical Materials 57 (2016) 24-41. doi:10.1016/j.jmbbm.2015.11.014.

[20] M. Vander Vorst, J. Stuhmiller, K. Ho, N. Yoganandan, F. Pintar, Statistically and Biomechanically Based Criterion for Impact-Induced Skull Fracture, Annual Proceedings Association for the Advancement of Automotive Medicine 47 (2003) 363-381.

[21] M. Vander Vorst, P. Chan, J. Zhang, N. Yoganandan, F. Pintar, A New Biomechanically-Based Criterion for Lateral Skull Fracture, Annual Proceedings Association for the Advancement of Automotive Medicine 48 (2004) 181-195.

[22] P. Verschueren, H. Delye, B. Depreitere, C. V. Lierde, B. Haex, D. Berckmans, I. Verpoest, J. Goffin, J. Vander Sloten, G. Van der Perre, A new test set-up for skull fracture characterisation, Journal of Biomechanics 40 (15) (2007) 3389-3396. doi:10.1016/j.jbiomech.2007.05.018. 
[23] A. G. Monea, Biomechanical Characterization of Bicycle Accidents Related Head Injuries, Phd thesis, KU Leuven (2013).

[24] R. Willinger, B. M. Diaw, H.-s. Kang, Finite element modelling of skull fractures caused by direct impact, International Journal of Crashworthiness 5 (3) (2000) 249-258. doi:10.1533/cras.2000.0139.

[25] D. Sahoo, C. Deck, N. Yoganandan, R. Willinger, Anisotropic composite human skull model and skull fracture validation against temporo-parietal skull fracture, Journal of the Mechanical Behavior of Biomedical Materials 28 (2013) 340-353. doi:10.1016/j.jmbbm.2013.08.010.

[26] Z. Asgharpour, D. Baumgartner, R. Willinger, M. Graw, S. Peldschus, The validation and application of a finite element human head model for frontal skull fracture analysis, Journal of the Mechanical Behavior of Biomedical Materials 33 (2014) 16-23. doi:10.1016/j.jmbbm.2013.02.010.

URL http://dx.doi.org/10.1016/j.jmbbm.2013.02.010

[27] D. T. Kemmoku, L. Serenó, J. San, J. Ciurana, A novel simplified 3D skull model to predict cranial fracture patterns, International Journal of Computer Integrated Manufacturing 27 (10) (2014) 927-935. doi: 10.1080/0951192X.2013.834470.

URL http://dx.doi.org/10.1080/0951192X.2013.834470

[28] Y. Zhan, A. T. Eggebrecht, P. Joseph, H. Dehghani, Image quality analysis of high-density diffuse optical tomography incorporating a subject-specific head model, Frontiers in Neuroenergetics 4 (May) (2012) 1-9. doi:10. 3389/fnene. 2012.00006 .

[29] K. M. Tse, L. B. Tan, S. J. Lee, S. P. Lim, H. P. Lee, Development and validation of two subject-specific finite element models of human head against three cadaveric experiments, International Journal for Numerical Methods in Biomedical Engineering 30 (2014) 397-415. doi:10.1002/cnm. 
[30] J. Huang, D. Raymond, W. Shen, J. Stuhmiller, G. Crawford, C. Bir, Development and Validation of a Subject-Specific Finite Element Model for Skull Fracture Assessment, ASME International Mechanical Engineering Congress and Exposition 2 (2011) 31-40.

[31] C. Zhou, T. B. Khalil, A. I. King, A New Model Comparing Impact Responses of the Homogeneous and Inhomogeneous Human Brain, in: Proc. of 39th Stapp Car Crash Conference, SAE Technical Paper, 1995, p. 17.

[32] J. H. McElhaney, J. L. Fogle, J. W. Melvin, R. R. Haynes, V. L. Roberts, N. M. Alem, Mechanical properties of cranial bone, Journal of Biomechanics 3 (5) (1970) 495-496,IN5,497-511. doi : 10.1016/0021-9290(70)90059-X.

URL http://www.scopus.com/inward/record.url?

eid $=2-$ s2 $.0-0014856907\{\&\}$ partner $I D=40\{\&\} \mathrm{md} 5=$

ff619bd80a62f304edfd321fcf507a9f

[33] D. W. Wagner, D. P. Lindsey, G. S. Beaupre, Deriving tissue density and elastic modulus from microCT bone scans, Bone 49 (5) (2011) 931-938. doi:10.1016/j. bone. 2011.07.021.

URL http://dx.doi.org/10.1016/j.bone.2011.07.021

[34] R. B. Martin, Porosity and Specific Surface of Bone, Critical Reviews in Biomedical Engineering 10 (3) (1983) 179-222.

[35] J. D. Currey, What Determines the Bending Strength of Compact Bone?, The Journal of Experimental Biology 202 (1999) 2495-2503.

[36] C. T. Leondes, Medical Imaging Systems Technology: Methods in General Anatomy, World Scientific, 2005.

[37] M. Fahlstedt, K. Baeck, P. Halldin, J. Van Der Sloten, J. Goffin, B. Depreitere, S. Kleiven, Influence of impact velocity and angle in a detailed reconstruction of a bicycle accident, in: Proceedings of the IRCOBI Conference, 2012, pp. 787-799. 
[38] J. W. Melvin, J. H. McElhaney, V. L. Roberts, Development of a mechanical model of the human head - Determination of tissue properties and synthetic substitute materials (1970). doi:10.4271/700903.

[39] D. Robbins, J. Wood, Determination of mechanical properties of the bones of the skull, Experimental Mechanics 9 (5) (1969) 236-240. doi:10.1007/ BF02326542.

[40] S. Kleiven, W. N. Hardy, Correlation of an FE Model of the Human Head with Local Brain Motion: Consequences for Injury Prediction, Stapp Car Crash Journal 46 (November) (2002) 123-144.

[41] J. Rösler, M. Bäker, H. Harders, Mechanical Behaviour of Engineering Materials: Metals, Ceramics, Polymers and Composites, Springer Science \& Business Media, 2007.

[42] A. Meynen, Analysing the Validity of a Skull Fracture Energy Criterion through Subject-Specific Finite Element Modelling of Head Impacts. Master Thesis. (2017).

[43] T. Belytschko, J. S.-J. Ong, W. K. Liu, J. M. Kennedy, Hourglass control in linear and nonlinear problems, Computer Methods in Applied Mechanics and Engineering 43 (3) (1984) 251-276. doi:10.1016/0045-7825(84) 90067-7.

[44] K. Baeck, Biomechanical modeling of head impacts A critical analysis of finite element modeling approaches., Ph.D. thesis, KU Leuven (2013).

[45] J. Ruan, P. Prasad, The effects of skull thickness variations on human head dynamic impact responses., Stapp car crash journal 45 (2001) 395-414.

[46] V. Hodgson, J. Brinn, L. Thomas, S. Greenberg, Fracture behavior of the skull frontal bone against cylindrical surfaces, Proceedings of the 14th Stapp Car Crash Conference (1970) 341-355. 
[47] E. S. Gurdjian, H. R. Lissner, J. E. Webster, F. R. Latimer, B. F. Haddad, Studies on experimental concussion: relation of physiologic effect to time duration of intracranial pressure increase at impact, Neurology 4 (9) (1954) 674. doi:10.1212/WNL.4.9.674.

[48] HEADS, HEADS-ITN, http://www.heads-itn.eu/ (2015). URL http://www.heads-itn.eu/

[49] A. Trotta, A. Ní Annaidh, R. Owen Burek, B. Pelgrims, J. Ivens, Evaluation of the head-helmet sliding properties in an impact test, Journal of Biomechanics 75 (2018) 28-34. doi:10.1016/j.jbiomech.2018.05.003.

[50] A. Trotta, D. Zouzias, G. De Bruyne, A. Ni Annaidh, The Importance of the Scalp in Head Impact Kinematics, Annals of Biomedical Engineering 46 (6) (2018) 831-840. doi:10.1007/s10439-018-2003-0.

[51] T. J. Horgan, M. D. Gilchrist, The creation of three-dimensional finite element models for simulating head impact biomechanics, International Journal of Crashworthiness 8 (4) (2003) 353-366. doi:10.1533/ijcr. 2003. 0243.

URL http://www.tandfonline.com/doi/abs/10.1533/ijcr.2003.0243

[52] S. Kleiven, Influence of Impact Direction on the Human Head in Prediction of Subdural Hematoma, Journal of Neurotrauma 20 (4) (2003) 365-379. doi: $10.1089 / 089771503765172327$.

URL http://www.liebertonline.com/doi/abs/10.1089/ 089771503765172327

[53] M. Salimi Jazi, A. Rezaei, G. Karami, F. Azarmi, M. Ziejewski, A computational study of influence of helmet padding materials on the human brain under ballistic impacts, Computer Methods in Biomechanics and Biomedical Engineering 17 (12) (2014) 1368-1382. doi:10.1080/10255842.2012. 748755 .

URL http://www.tandfonline.com/doi/abs/10.1080/10255842.2012. 748755 
[54] U.S. National Library of Medicine, Department of Health and Human Services: Visible Human Database (2000).

[55] H. Kang, R. Willinger, F. Turquier, A. Domont, X. Trosseille, C. Tarriere, Evaluation study of a 3D human head model against experimental data, in: Proc. of the 40th Stapp Car Crash Conference, 1996.

[56] F. A. Bandak, M. J. Vander Vorst, L. M. Stuhmiller, P. F. Mlakar, W. E. Chilton, J. H. Stuhmiller, Imaging-Based Computational and Experimental Study of Skull Fracture : Finite Element Model Development, Journal of Neurotrauma 12 (4) (1995) 679-689.

[57] L. Zhang, K. H. Yang, R. Dwarampudi, K. Omori, T. Li, K. Chang, W. N. Hardy, T. B. Khalil, A. I. King, Recent Advances in Brain Injury Research : A New Human Head Model Development and Validation, Stapp Car Crash Journal 45 (2001) 25.

[58] E. G. Takhounts, R. H. Eppinger, J. Q. Campbell, E. T. Rabih, E. D. Power, L. S. Shook, On the Development of the SIMon Finite Element Head Model, Stapp Car Crash Journal 47 (2003) 107-133.

[59] E. M. Lillie, J. E. Urban, S. K. Lynch, A. A. Weaver, J. D. Stitzel, Evaluation of skull cortical thickness changes with age and sex from computed tomography scans, Journal of Bone and Mineral Research 31 (2) (2016) 299-307.

[60] A. Post, D. Koncan, M. Kendall, J. Cournoyer, J. Clark, G. Kosiwka, W. Chen, A. Santiago de Grau, T. Hoshizaki, Analysis of Velocity Accuracy Using a Low-Cost Video Analysis Software, Sports Engineering (2018) 1-7. 


\section{Appendix A. Experimental Database}

Table A.6: Experimental database with the general and impact site properties of each specimen. The impact site is defined as the part of the head in line with the cylindrical impactor. The thicknesses are expressed in mean $\pm \mathrm{SD}$.

\begin{tabular}{|c|c|c|c|c|c|c|}
\hline ID & Impact Site & $\begin{array}{l}\text { Age } \\
{[y r s]}\end{array}$ & $\begin{array}{c}\text { Mass } \\
{[\mathrm{kg}]}\end{array}$ & $\begin{array}{c}\rho_{i m p} \\
{\left[\mathrm{~g} / \mathrm{cm}^{3}\right]}\end{array}$ & $\begin{array}{l}T_{\text {bone }} \\
{[\mathrm{mm}]}\end{array}$ & $\begin{array}{l}T_{\text {scalp }} \\
{[\mathrm{mm}]}\end{array}$ \\
\hline 1 & F & 98 & 2.52 & 0.87 & $3.89 \pm 2.50$ & $3.43 \pm 2.14$ \\
\hline 2 & F & 73 & 2.41 & 1.08 & $4.84 \pm 2.15$ & $2.52 \pm 1.91$ \\
\hline 3 & F & 68 & 2.78 & 1.25 & $4.34 \pm 1.90$ & $2.87 \pm 1.98$ \\
\hline 5 & $\mathrm{~T}$ & 72 & 2.74 & 1.32 & $3.12 \pm 1.81$ & $9.22 \pm 2.43$ \\
\hline 6 & $\mathrm{~T}$ & 102 & 2.69 & 0.91 & $5.53 \pm 2.12$ & $5.11 \pm 2.24$ \\
\hline 7 & $\mathrm{~T}$ & 80 & 2.58 & 1.34 & $2.13 \pm 1.62$ & $5.67 \pm 2.59$ \\
\hline 8 & $\mathrm{~T}$ & 71 & 2.95 & 1.07 & $2.63 \pm 1.73$ & $8.64 \pm 2.22$ \\
\hline 9 & $\mathrm{~T}$ & 78 & 2.77 & 1.59 & $3.98 \pm 1.93$ & $7.47 \pm 2.64$ \\
\hline 10 & $\mathrm{~T}$ & 80 & 2.98 & 1.49 & $2.76 \pm 1.99$ & $7.35 \pm 5.67$ \\
\hline 11 & $\mathrm{~T}$ & 52 & 2.60 & 1.24 & $2.84 \pm 1.72$ & $6.13 \pm 4.56$ \\
\hline 12 & $\mathrm{~T}$ & 69 & 2.64 & 1.43 & $3.89 \pm 1.96$ & $3.84 \pm 2.00$ \\
\hline 13 & $\mathrm{~T}$ & 72 & 2.23 & 0.87 & $2.34 \pm 1.23$ & $5.72 \pm 2.63$ \\
\hline 14 & $\mathrm{~T}$ & 88 & 2.76 & 0.84 & $2.17 \pm 1.68$ & $7.37 \pm 2.54$ \\
\hline 16 & $\mathrm{O}$ & 85 & 2.63 & 1.09 & $7.75 \pm 2.61$ & $4.82 \pm 1.55$ \\
\hline 18 & $\mathrm{O}$ & 98 & 2.51 & 1.11 & $5.76 \pm 1.99$ & $2.78 \pm 1.95$ \\
\hline 19 & $\mathrm{O}$ & 78 & 3.27 & 1.28 & $6.79 \pm 2.75$ & $3.77 \pm 1.81$ \\
\hline 20 & $\mathrm{O}$ & 60 & 3.05 & 1.15 & $5.31 \pm 1.80$ & $5.95 \pm 1.79$ \\
\hline 21 & $\mathrm{O}$ & 82 & 3.12 & 1.03 & $5.64 \pm 2.15$ & $8.89 \pm 2.37$ \\
\hline
\end{tabular}

$\rho_{i m p}$ : skull bone density at impact site, $T_{\text {bone }}$ : skull bone thickness at impact site, $T_{\text {scalp }}$ : scalp layer thickness at impact site, $F$ : frontal, $T$ : temporal, $O$ : occipital. 


\section{Appendix B. Simulation Results}

Table B.7: Overview of the output data of the experiments and simulations.

\begin{tabular}{|c|c|c|c|c|c|c|c|c|c|c|}
\hline \multirow[t]{2}{*}{ ID } & \multirow[t]{2}{*}{ Impact Site } & \multirow{2}{*}{$\begin{array}{c}F_{\exp } \\
{[N]} \\
\end{array}$} & \multicolumn{2}{|c|}{$F_{\text {sim }}$} & \multirow{2}{*}{$\begin{array}{c}\text { Dispexp } \\
{[m m]}\end{array}$} & \multicolumn{2}{|c|}{$D_{i s p}$ sim } & \multirow{2}{*}{$\begin{array}{c}E_{e x p}^{f r a c} \\
{[J]} \\
\end{array}$} & \multicolumn{2}{|c|}{$E_{\text {sim }}^{\text {frac }}$} \\
\hline & & & $\begin{array}{c}\text { Homog. } \\
{[N]}\end{array}$ & $\begin{array}{c}\text { Sub.-spec. } \\
{[N]}\end{array}$ & & $\begin{array}{c}\text { Homog. } \\
{[\mathrm{mm}]}\end{array}$ & $\begin{array}{c}\text { Sub.-spec. } \\
{[\mathrm{mm}]}\end{array}$ & & $\begin{array}{c}\text { Homog. } \\
{[\mathrm{J}]}\end{array}$ & $\begin{array}{c}\text { Sub.-spec } \\
{[\mathrm{J}]}\end{array}$ \\
\hline 1 & $\mathrm{~F}$ & 7379 & 10248 & 11724 & 1.80 & 2.39 & 2.73 & 6.32 & 8.82 & 12.97 \\
\hline 2 & $\mathrm{~F}$ & 9870 & 8025 & 10383 & 3.87 & 1.82 & 2.18 & 14.97 & 5.20 & 8.46 \\
\hline 3 & $\mathrm{~F}$ & 12909 & 5968 & 9451 & 5.79 & 2.06 & 2.35 & 16.34 & 4.32 & 7.70 \\
\hline 5 & $\mathrm{~T}$ & 7991 & 3991 & 7249 & 5.23 & 3.98 & 4.08 & 4.30 & 5.59 & 13.92 \\
\hline 6 & $\mathrm{~T}$ & 5171 & 5980 & 6819 & 5.61 & 1.88 & 2.07 & 7.28 & 5.16 & 6.33 \\
\hline 7 & $\mathrm{~T}$ & 4360 & 1206 & 1055 & 5.89 & 3.13 & 2.73 & 9.45 & 1.70 & 1.11 \\
\hline 8 & $\mathrm{~T}$ & 5532 & 3521 & 2526 & 4.24 & 5.02 & 4.00 & 13.01 & 6.39 & 3.23 \\
\hline 9 & $\mathrm{~T}$ & 9832 & 6218 & 9732 & 4.04 & 3.26 & 3.70 & 21.11 & 7.55 & 12.60 \\
\hline 10 & $\mathrm{~T}$ & 10206 & 3149 & 4413 & 4.08 & 2.78 & 3.17 & 35.34 & 2.88 & 4.71 \\
\hline 11 & $\mathrm{~T}$ & 7264 & 2260 & 1747 & 2.09 & 3.44 & 2.58 & 8.31 & 2.61 & 1.44 \\
\hline 12 & $\mathrm{~T}$ & 9864 & 6398 & 7453 & 3.13 & 2.29 & 2.31 & 18.64 & 5.79 & 6.65 \\
\hline 13 & $\mathrm{~T}$ & 10250 & 1801 & 2805 & 4.07 & 2.85 & 4.10 & 10.53 & 1.63 & 4.64 \\
\hline 14 & $\mathrm{~T}$ & 2895 & 1860 & 2059 & 4.33 & 2.18 & 2.30 & 3.12 & 1.77 & 1.96 \\
\hline 16 & $\mathrm{O}$ & 12632 & 9635 & 8718 & 4.07 & 3.19 & 2.84 & 13.22 & 10.41 & 7.81 \\
\hline 18 & $\mathrm{O}$ & 14052 & 7674 & 11963 & 2.07 & 2.10 & 2.45 & 13.74 & 6.76 & 12.64 \\
\hline 19 & $\mathrm{O}$ & 14259 & 5663 & 5809 & 4.48 & 2.42 & 2.38 & 16.65 & 4.94 & 5.00 \\
\hline 20 & $\mathrm{O}$ & 10473 & 7357 & 10895 & 4.64 & 3.14 & 3.38 & 17.53 & 9.67 & 13.61 \\
\hline 21 & $\mathrm{O}$ & 5868 & 8446 & 13094 & 9.95 & 3.73 & 4.33 & 35.37 & 12.01 & 20.67 \\
\hline \multicolumn{11}{|c|}{ Frontal } \\
\hline Mean & & 10053 & 8080 & 10520 & 3.81 & 2.09 & 2.42 & 12.54 & 6.11 & 9.71 \\
\hline $\mathrm{SD}$ & & 2769 & 2140 & 1142 & 1.98 & 0.29 & 0.29 & 5.43 & 2.39 & 2.85 \\
\hline \multicolumn{11}{|c|}{ Temporal } \\
\hline Mean & & 7337 & 3638 & 4586 & 4.27 & 3.08 & 3.10 & 13.11 & 4.11 & 5.66 \\
\hline $\mathrm{SD}$ & & 2714 & 1957 & 3002 & 1.13 & 0.93 & 0.81 & 9.68 & 2.22 & 4.45 \\
\hline \multicolumn{11}{|c|}{ Occipital } \\
\hline Mean & & 11457 & 7755 & 10096 & 5.04 & 2.92 & 3.08 & 19.30 & 8.76 & 11.95 \\
\hline $\mathrm{SD}$ & & 3470 & 1462 & 2889 & 2.93 & 0.65 & 0.81 & 9.17 & 2.86 & 6.01 \\
\hline
\end{tabular}

$F_{\text {exp }}$ : experimental measured peak force, $F_{\text {sim }}$ : peak force recorded in FE simulation for homogeneous and subject-specific material model, Disp $p_{\exp }$ : experi-

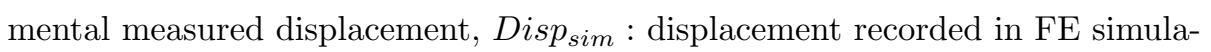
tion for homogeneous and subject-specific material model, $E_{\text {exp }}^{\text {frac }}$ : experimental fracture strain energy, $E_{\text {sim }}^{\text {frac }}$ : fracture strain energy of the FE simulation for homogeneous and subject-specific material model. 


\section{Appendix C. Error Homogeneous and Subject-Specific Material Model for the Peak Fracture Force, Displacement and Frac- ture Strain Energy}

Table C.8: Overview of the error per case for the homogeneous and subject-specific material model for the peak fracture force, the displacement and the fracture strain energy.

\begin{tabular}{cccccccc}
\hline \multirow{2}{*}{ ID } & \multirow{2}{*}{ Impact Site } & \multicolumn{2}{c}{ Error Peak Fracture Force } & \multicolumn{2}{c}{ Error Displacement } & \multicolumn{2}{c}{ Error Fracture Strain Energy } \\
& & Homog. & Sub.-spec. & Homog. & Sub.-spec. & Homog. & Sub.-spec. \\
\hline 1 & $\mathrm{~F}$ & 0.3888 & 0.5888 & 0.3278 & 0.5167 & 0.3956 & 1.0522 \\
2 & $\mathrm{~F}$ & 0.1869 & 0.0520 & 0.5297 & 0.4367 & 0.6526 & 0.4349 \\
3 & $\mathrm{~F}$ & 0.5377 & 0.2679 & 0.6442 & 0.5941 & 0.7356 & 0.5288 \\
5 & $\mathrm{~T}$ & 0.5006 & 0.0929 & 0.2390 & 0.2199 & 0.3000 & 2.2372 \\
6 & $\mathrm{~T}$ & 0.1564 & 0.3187 & 0.6649 & 0.6310 & 0.2912 & 0.1305 \\
7 & $\mathrm{~T}$ & 0.7234 & 0.7580 & 0.4686 & 0.5365 & 0.8201 & 0.8825 \\
8 & $\mathrm{~T}$ & 0.3635 & 0.5434 & 0.1840 & 0.0566 & 0.5088 & 0.7517 \\
9 & $\mathrm{~T}$ & 0.3676 & 0.0102 & 0.1931 & 0.0842 & 0.6423 & 0.4031 \\
10 & $\mathrm{~T}$ & 0.6915 & 0.5676 & 0.3186 & 0.2230 & 0.9185 & 0.8667 \\
11 & $\mathrm{~T}$ & 0.6889 & 0.7595 & 0.6459 & 0.2344 & 0.6859 & 0.8267 \\
12 & $\mathrm{~T}$ & 0.3514 & 0.2444 & 0.2684 & 0.2620 & 0.6894 & 0.6432 \\
13 & $\mathrm{~T}$ & 0.8243 & 0.7263 & 0.2998 & 0.0074 & 0.8452 & 0.5594 \\
14 & $\mathrm{~T}$ & 0.3575 & 0.2888 & 0.4965 & 0.4688 & 0.4327 & 0.3718 \\
16 & $\mathrm{O}$ & 0.2373 & 0.3098 & 0.2162 & 0.3022 & 0.2126 & 0.4092 \\
18 & $\mathrm{O}$ & 0.4539 & 0.1487 & 0.0145 & 0.1836 & 0.5080 & 0.0801 \\
19 & $\mathrm{O}$ & 0.6028 & 0.5926 & 0.4598 & 0.4688 & 0.7033 & 0.6997 \\
20 & $\mathrm{O}$ & 0.2975 & 0.0403 & 0.3233 & 0.2716 & 0.4484 & 0.2236 \\
21 & $\mathrm{O}$ & 0.4393 & 1.2314 & 0.6251 & 0.5648 & 0.6604 & 0.4156 \\
\hline
\end{tabular}




\section{Appendix D. Sensitivity Study - Scalp Thickness}

Table D.9: Peak force, contact area, scalp and skull strain energy for the frontal (ID 2), temporal (ID 11) and occipital (ID 19) cases with half, original and double the scalp thickness.

\begin{tabular}{ccccc}
\hline Scalp Thickness $[\mathrm{mm}]$ & Peak Force $[N]$ & Contact Area $\left[\mathrm{mm}^{2}\right]$ & Scalp Strain Energy $[J]$ & Skull Strain Energy $[J]$ \\
\hline Frontal & & & & \\
1.26 & 22479 & 2761 & 2.98 & 5.96 \\
2.52 & 20737 & 3029 & 4.89 & 5.80 \\
5.04 & 18118 & 3025 & 7.59 & 4.92 \\
Temporal & & & & 3.87 \\
3.06 & 14927 & 3100 & 3.19 & 3.48 \\
6.13 & 11871 & 3026 & 4.57 & 2.84 \\
12.26 & 9535 & 2960 & 7.15 & 8.00 \\
Occipital & & & & 9.48 \\
1.85 & 37946 & 3075 & 20.28 & 6.86 \\
3.77 & 38329 & 3194 & 30.20 & \\
7.54 & 30921 & 2968 &
\end{tabular}

